\title{
Research on Lean Planning and Optimization for Precast Component Production Based on Discrete Event Simulation
}

\author{
Zhenmin Yuan (D), ${ }^{1,2}$ Yaning Qiao, ${ }^{1,2}$ Yaru Guo, ${ }^{1}$ Yaowu Wang, ${ }^{3}$ Chen Chen, ${ }^{4}$ \\ and Wenshun Wang $\mathbb{D}^{1,2}$ \\ ${ }^{1}$ School of Mechanics and Civil Engineering, China University of Mining and Technology, Xuzhou 221116, China \\ ${ }^{2}$ Research Center for Digitalized Construction and Knowledge Engineering, China University of Mining and Technology, \\ Xuzhou 221116, China \\ ${ }^{3}$ School of Civil Engineering, Harbin Institute of Technology, Harbin 150001, China \\ ${ }^{4}$ Nantong Prefabricated Buildings and Intelligent Structures Institute, Nantong 226000, China \\ Correspondence should be addressed to Wenshun Wang; kdwangws@cumt.edu.cn
}

Received 19 August 2020; Revised 20 October 2020; Accepted 26 October 2020; Published 7 November 2020

Academic Editor: Zhen Lei

Copyright ( $\odot 2020$ Zhenmin Yuan et al. This is an open access article distributed under the Creative Commons Attribution License, which permits unrestricted use, distribution, and reproduction in any medium, provided the original work is properly cited.

\begin{abstract}
Component factories are experiencing the problems associated with lean production, especially the accuracy of production time prediction and the unnecessary waste in terms of time and resource utilization. In order to solve these problems, a discrete event simulation- (DES-) based lean planning and optimization method for precast component production is proposed by integrating the complexity assessment (CS), discrete event simulation (DES), and lean management (LM). The method includes three submodels: improved production planning, DES, and lean analysis and optimization. In the submodel of improved production planning, a complexity evaluation index system for precast components is established through investigating five component factories, consulting seven domain experts and analysing relevant literature. In the submodel of DES, the DES technique is adopted to simulate and analyse the production activities of precast components. The submodel of lean analysis and optimization provides multidimensional analysis, comparative analysis, and suggestions. Finally, a detailed production case is selected to simulate and test the proposed method. The important findings are as follows: (1) this method can minimize the difference between the processing time of each workstation to avoid bottleneck stations as much as possible; (2) this method can capture the uncertainty during precast component production, and the most likely production time calculated by the method is 12.05 hours instead of the 11.50 hours originally estimated by the component factory; (3) this method can identify some unnecessary waste in the production process of precast components, including less than $50 \%$ utilization of workstations and unnecessary equipment purchases; (4) this method also provides some suggestions regarding production optimization. Due to the particularity of precast component production, it further expands the boundary of lean production methodology from the perspective of the construction industry rather than the manufacturing industry. The proposed method assists component factories in planning and optimizing the precast component production when they make detailed production plans.
\end{abstract}

\section{Introduction}

Since prefabricated buildings earn a lot of time in the global fight against the new coronavirus "COVID-19," they attract more global attention than other types of buildings. Prefabricated buildings, a sustainable, and cleaner technology [1] are once considered a preferred choice to balance economic, environmental, and social benefits [2]. A large number of scholars have conducted in-depth research on prefabricated buildings in the aspects of environment $[3,4]$, risks [5-7], and virtual construction $[8,9]$. However, the development of prefabricated buildings is still in its infancy stage owing to the high total cost, insignificant environment effectiveness, and unclear social benefit. What is even more worrying is that the higher prefabrication rate would lead to the higher total cost [10]. This phenomenon is not conducive to the sustainable development of prefabricated buildings. Hence, some experts are invited to identify the key stages 
leading to incremental costs. The result shows that incremental costs are mainly from the production and transportation stages of precast components. This result is consistent with Chen et al. [11] who think that the high cost of prefabricated buildings is mainly attributed to the higher production cost.

Lean production theory believes that the waste (e.g., time and resources) is an important cause of high production costs [12]. Time and cost are inseparable in the precast component production system. In addition to higher production costs, component factories are also facing the heavy pressure from on-time delivery [13], which affects the formulation of production plans. According to the previous investigation and consultation for several component factories, component factories expect that takt time without steam curing will be controlled within 15 minutes. This rough production planning is simple but hides a lot of valuable information. Hence, component factories have not yet found a suitable method regarding the planning and optimization for precast component production although they are very clear about their own needs and responsibilities. After searching and analysing relevant literature, we find that the planning and optimization for precast component production are mainly achieved in the following ways: the resource and cost optimization for complex molds [14], the layout planning of precast components under the constraints of mold platen utilization [15], the planning of crew configurations based on genetic algorithm [16], and the production planning system integrating multiple artificial intelligence technologies [17]. However, these related studies ignore some practical problems, including the uncertainty of the production process, the complex evaluation of precast components, and the unnecessary waste during component production.

According to component factory investigation, expert consultation, and existing literature analysis, this study aims to improve the accuracy of production time prediction by capturing the uncertainty during precast component production. On this basis, this study is further intended to eliminate unnecessary waste in terms of time and resource utilization. It not only involves the survival of precast component factories but also affects the sustainability of the entire prefabricated construction industry. Firstly, the existing relevant literature is reviewed and analysed. Secondly, the DES-based lean planning and optimization method for precast component production, a new integrated approach, is proposed by combining the complexity assessment (CS), discrete event simulation (DES), and lean management (LM) on the basis of the existing production planning. Thirdly, a production case from a component factory is used to simulate and test this methodology. Fourthly, the obtained results are analysed in depth. Finally, conclusions and future work are summarized.

\section{Literature Review}

2.1. Production Line and Process. Precast components making up prefabricated buildings are produced at a factory. The basic production process includes cleaning mold, binding steel, pouring concrete, curing component, and releasing mold [18]. However, different types of precast components vary in the details of production process. Each type of precast component has a corresponding production line [19]. The existing production lines are divided into two categories: fixed mold platen and mobile mold platen [20]. Most precast components are produced by using mobile mold platen, including semiprecast slabs, lightweight partition boards, and precast wallboards. Improvements in production process attract the attention from scholars. Chen et al. [21] created more efficient precast process from the perspective of process reengineering. Ochoa [22] developed a more reliable production planning process with the help of the last planner system (LPS). Han et al. [23] applied an automated postsimulation tool to improve the production line of prefabricated buildings. However, once a production line is built in reality, all corresponding processes will be determined and not easy to change. Bottleneck stations are not welcomed during precast component production. Two ways to deal with bottleneck stations are discovered by Arashpour et al. [24] and Arashpour et al. [25]: one is to set the work-in-process (WIP) buffers, and the other is to optimize the process and resource. From an economic perspective, the latter seems to be given priority.

2.2. Production Planning and Scheduling. Production planning and scheduling play a crucial role in the on-time delivery and other benefits of precast components. There is a sequential and cross relationship between them, which have been studied together in many existing literature. Time is the most basic variable for production planning and scheduling. Li et al. [26] studied schedule risks in prefabrication housing production. Gantt chart is a common tool to make and illustrate schedules $[27,28]$. Discrete event simulation (DES) analyses what-if questions regarding scheduling and management $[29,30]$. However, DES is more flexible than Gantt chart in terms of capturing uncertain information. Demiralp et al. [31] used Arena software, a DES tool, to simulate the total time and error of using RFID technology in the production, transfer, and installation of precast panels. Tommelein [32] adopted the STROBOSCOPE computer system, a DES tool, to simulate the pipe-spool installation process and proved that the "pull" technique helped to improve the performance of the process.

Some studies regarding the production planning and scheduling of precast components are mainly for a single production line. Khalili and Chua [14] adopted a mold adaptability matrix to efficiently utilize complex molds in production platform. Wang et al. [15] offered a model of prefabrication production planning to maximize the average utilization rate of pallets. In contrast, the scheduling of multiple production lines is gradually becoming an issue. Wang and $\mathrm{Hu}$ [33] established a two-level rescheduling model of precast production with multiple production lines. However, regardless of the research on single production lines or multiple production lines, the accuracy of production time prediction has not been paid enough attention and effectively solved. The application and development of 
methods have always been the focus of scholars. Genetic algorithm (GA) is widely adopted in the production planning and scheduling of precast components, such as Ko [34], Ma et al. [35], Wang et al. [36], and Wang et al. [37], as well as Yang et al. [38]. Podolski and Rejment [39] proposed a production scheduling model of precast components based on the simulated annealing metaheuristic algorithm. Altaf et al. [40] developed a production planning and control system for a panelised home production facility. All abovementioned studies seem to have not taken into account the complexity of precast components, which will aggravate the unevenness of the flowing rhythm between mold platens so as to cause further waste.

2.3. Lean Management. Lean concepts derived from the Japanese automotive industry [41] aim to minimize the waste in processes and maximize the value of products [42]. Koskela [43] put forward the application of new production philosophies to construction in September 1992. Some new production philosophies (especially lean management) have developed rapidly in the construction industry. Lean management has been widely used in the construction industry so far, such as BIM and lean synergies [44], lean design management [45], and lean talent management [46], as well as lean principles in construction projects [47]. For component factories, the products refer to various precast components. Lean management will reduce costs and increase efficiency in the production process of precast components for prefabricated buildings. Hence, lean management has always been valued by component factories and scholars. Yu et al. [48] developed a production system for the effective application of lean tools in precast component production. Heravi and Firoozi [49] used value stream mapping to identify the wastes in production, diagnose their fundamental causes, and propose improvements. Innella et al. [50] discussed the implementation of lean techniques in all production process stages of the prefabricated building industry. However, some techniques (e.g., value stream mapping) in lean management can handle determined time instead of floating time. Discrete event simulation is commonly used to capture and deal with time uncertainty, and some unknown valuable information can be obtained from the processing results. The studies combining lean management with discrete event simulation are rare, which makes it difficult for lean management to consider the uncertainty of time.

By reviewing the production line and process, the production planning, and scheduling as well as the lean management, the following information can be obtained: (1) direct related studies are few but lay the foundation for the planning and optimization for precast component production; (2) although some studies are not specifically aimed at the planning and optimization for precast component production, they provide some concepts and methods with reference value, such as the DES, GA, and lean management; (3) the methods from different studies have the feasibility of complementary advantages so as to achieve the effect of " $1+1>2$ "; (4) all studies do not take into account the complexity of precast components.

\section{Research Methodology}

So far, the body of knowledge related to the existing production planning method for precast components is fragmented. Therefore, it is necessary to sort out and summarize the body of knowledge. Then, a framework for DES-based lean planning and optimization method is proposed on the basis of the existing production planning method.

\subsection{Existing Production Planning Method for Precast} Components. Component factories pay close attention to cost reduction and benefit increase. A direct and effective way is to strengthen lean manufacturing, which continuously improves resource utilization and reduce unnecessary waste. In order to sort out the existing production planning method, five component factories were surveyed on-site and seven experts were consulted, as shown in Table 1. The five component factories are located in Heilongjiang, Jiangsu, and Guangdong of China, respectively. The seven experts have worked in component factories for more than two years. Three experts adopt face-to-face consultation, and the other four experts conduct online consultation via WeChat, which is a popular online app for communication in China. Figure 1 indicates the production process of a component factory under investigation. Compared with other precast components, precast wallboards and semiprecast slabs are processed on the flow production line, which is an important symbol for component factories from manual production to industrial production.

The production plans of precast components in reality include a total supply plan, a monthly production plan, a weekly production plan, and a daily production plan [51]. This is the process of refining plans. The production capability analysis is the premise and foundation of all production plans. After multiple consultations and feedbacks, the framework for the existing production planning method corresponding to the daily production plan is summarized, as shown in Figure 2.

Step 1: analyse production line and its workstations. Step 2: plan component layout on mold platen. Step 3: if the high utilization of mold platen is not met, then return to the step 2; otherwise, proceed to the next step. Step 4: arrange workers and other resources to regulate and control workstation time. Step 5: determine takt time to calculate the production time. Step 6: if the production time does not meet the daily production plan, then multiple shifts per day are recommended until the daily production plan is met; otherwise, end the planning process to obtain a detailed and feasible daily production scheme.

3.2. Framework for DES-Based Lean Planning and Optimization Method. It is a kind of classical scientific thinking to analyse the deficiency of existing methods and make improvements. We find that the existing production planning method ignores the complexity assessment (CS) of precast components. Besides, it is also unable to capture the uncertainty in production and make lean analysis of the production process. Hence, the related consultation and 
TABLE 1: Basic information of component factory experts.

\begin{tabular}{lccc}
\hline Code & Location of component factory & Position in component factory & Working years in component factory \\
\hline Expert 1 & Heilongjiang & Technical engineer & 10 \\
Expert 2 & Jiangsu & Factory manager & 3 \\
Expert 3 & Jiangsu & Technical engineer & 10 \\
Expert 4 & Jiangsu & Technical engineer & 3 \\
Expert 5 & Jiangsu & Technical engineer & 5 \\
Expert 6 & Guangdong & Chief engineer & 4 \\
Expert 7 & Guangdong & Laboratory director & 2 \\
\hline
\end{tabular}

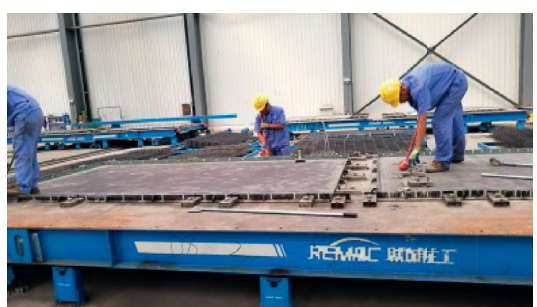

(a)

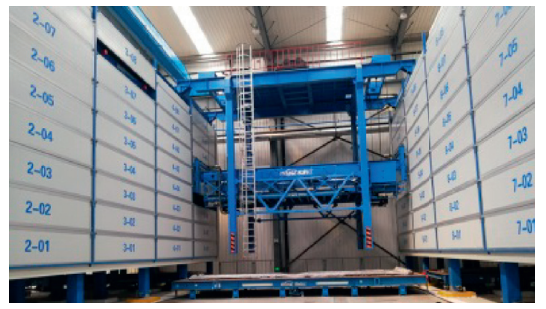

(d)

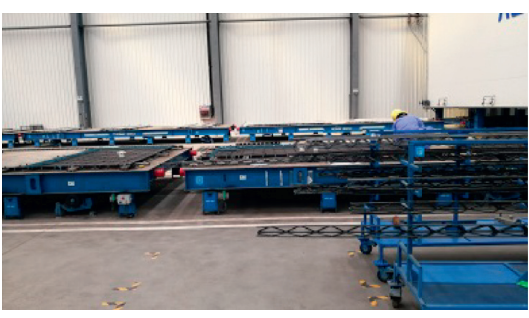

(b)

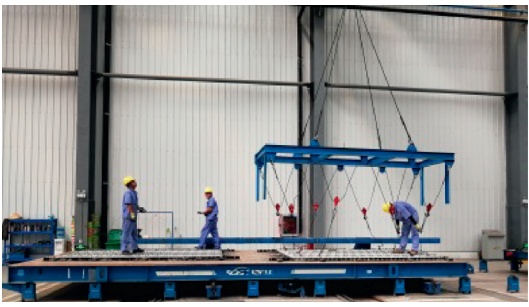

(e)

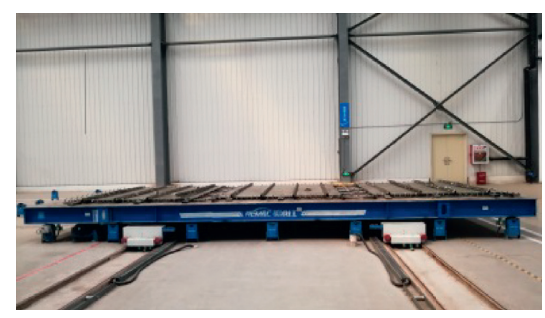

(c)

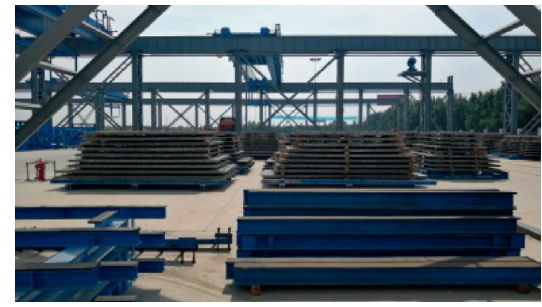

(f)

Figure 1: Production process of a component factory under investigation. (a) Cleaning workstation. (b) Steel installation workstation. (c) Resting workstation. (d) Curing kiln. (e) Mold releasing workstation. (f) Stacking area.

verification work are carried out again. After many in-depth discussions with the above experts, we find that the complexity of precast components should also be regarded as a constraint of component layout on mold platen. The combination of precast components with higher complexity and the combination of precast components with lower complexity are not the optimal layout while the combination of precast components under equilibrium is recognized as the optimal layout. The combination of precast components under equilibrium can make the duration of a mold platen at each workstation tend to be equal. With a holistic review of previous literature, we find that discrete event simulation and lean management can assist in the realization of lean planning. Discrete event simulation (DES) provides an opportunity to capture the uncertainty of production operations [52, 53]. Lean management (LM) provides some valuable index analyses, including production time analysis [54], bottleneck workstation analysis [55], resource utilization analysis [56], and cost-benefit analysis [57]. Hence, CS, DES, and LM are combined with the existing production planning to form a DES-based lean planning and optimization method, as shown in Figure 3.

The DES-based lean planning and optimization method is divided into three submodels, namely, improved production planning, discrete event simulation, and lean analysis and optimization. Improved production planning is the premise of discrete event simulation as well as lean analysis and optimization. Discrete event simulation builds the connection between improved production planning and lean analysis and optimization. Lean analysis and optimization have a feedback effect on improved production planning.

3.2.1. Submodel of Improved Production Planning. The submodel of improved production planning adds the complexity evaluation of precast components to the existing production planning. The identification of complexity evaluation indices for precast components is an important and urgent challenge to be solved. If all types of precast components are considered during index identification, then the number of indices will become extremely large. Hence, this study is limited to precast wallboards and semiprecast slabs suitable for assembly lines. Firstly, we search China National Knowledge Infrastructure and Web of Science by topic search within our capabilities, but no relevant literature is found. The topics include precast components, precast wallboards, semiprecast slabs, and complexity. This means that the complexity indices of precast components are relatively new and unknown to existing research. Ji et al. [58] measured the complexity of prefabricated construction products via quality performance-based indicators, but they 


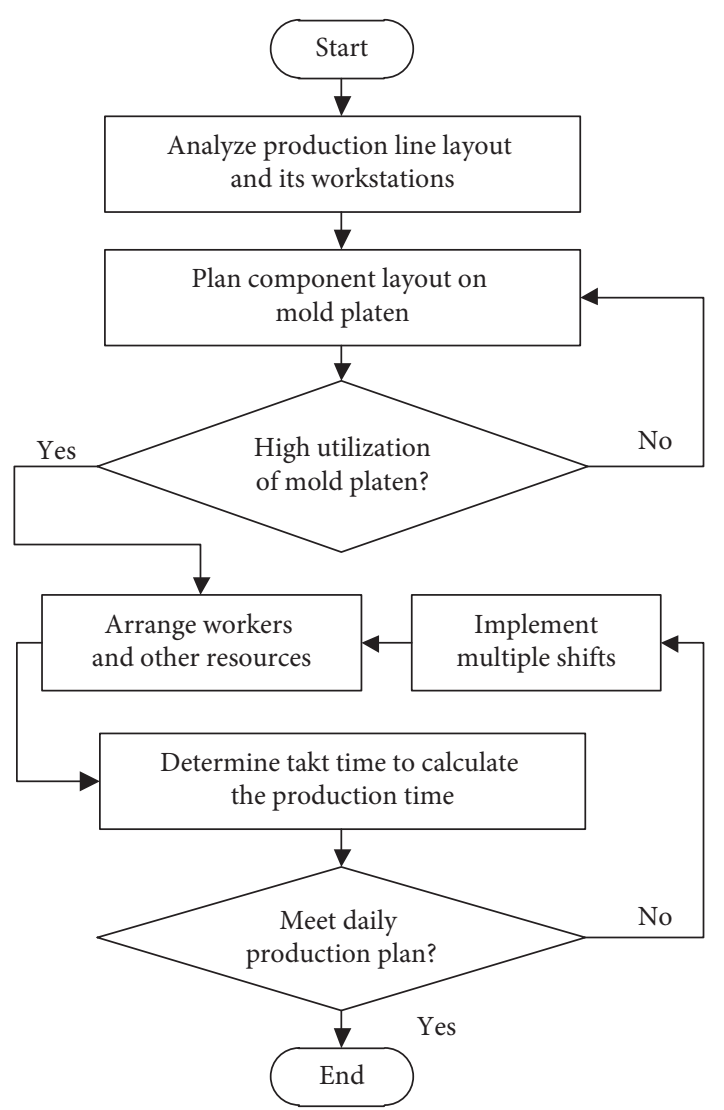

FIGURE 2: Framework for the existing production planning method.

did not clarify what these indicators are. Although there is no lack of research on product complexity in the manufacturing industry [59-61], product attributes vary greatly between the construction industry and the manufacturing industry. Secondly, we have to identify the complexity evaluation indices for precast components through the investigation, consultation, and practice. The investigated companies and the consulted experts are as the same as the information listed in Table 1. After multiple rounds of feedback, the complexity evaluation index system for precast components is established, as shown in Table 2.

The complexity of a precast component depends on its shape, composition, and processing technology. Since different types of precast components differ in their complexity evaluation indices, their weights have to be determined in specific production cases. The weight of an index depends on how much the index affects the production time. These indices are divided into two categories: easy-to-quantify indices and difficult-to-quantify indices. The scoring set of each difficult-to-quantify index is quantified by the Likert scale, such as " $1=$ extremely simple," " $2=$ more simple," " 3 = generally complex," " $4=$ more complex," and " $5=$ extremely complex". The simplest or most complex indices serve as a scoring reference for a certain index. The value of each easy-to-quantify index also needs to be converted into a range of 1 to 5. For example, the second-class index "cast times" is an easy-to-quantify index. If a precast component only needs one-time cast, then its score is 1 . The "cast times" is positively related to the scores. However, if a precast component needs more than five-times cast, then its score is still 5. The complexity calculation of a precast component is shown in Formula (1). $f$ represents the complexity of a precast component. $w_{i}$ represents the weight of the ith index. $r_{i}$ represents the score of the ith index.

$$
f=\left[w_{1}, w_{2}, \ldots, w_{i}, \ldots, w_{12}\right] \times\left[r_{1}, r_{2}, \ldots, r_{i}, \ldots, r_{12}\right]^{\prime} .
$$

3.2.2. Submodel of Discrete Event Simulation. The existing calculation method of the production time for precast components is mainly based on takt time, which is a time value after comprehensively considering the processing time of each workstation. Its principle is shown in formula (2). T represents the production time of a batch of precast components. $t$ represents takt time. $n$ represents the number of mold platens. $t_{0}$ represents the steam curing time in curing kiln. The corresponding relationship between mold platens and precast components is that more than one precast component can be placed on one mold platen.

$$
T=t \times n+t_{0} .
$$

The processing time of each workstation is not a fixed value, and they are also different from each other. Hence, the existing calculation method ignores the uncertainty in production. Discrete event simulation is an event-driven and state-hopping subsystem, which provides an opportunity to capture the uncertainty. The occurrence of an event is uncertain, but follows a certain probability distribution. By analysing and comparing many common continuous distributions, uniform distribution and triangular distribution should be used in DES due to considering limited sample data, as shown in formulas (3) and (4).

$$
\begin{aligned}
& f(x)= \begin{cases}\frac{1}{b-a}, & a<x<b, \\
0, & \text { else, }\end{cases} \\
& g(x)=\left\{\begin{array}{cc}
\frac{2(x-a)}{(b-a)(c-a)}, & a \leq x \leq c . \\
\frac{2(b-x)}{(b-a)(b-c)}, & c<x \leq b .
\end{array}\right.
\end{aligned}
$$

The $f(x)$ or $g(x)$ is a probability density function. $x$ is an independent variable and usually represents time. The $a, b$, and $c$ respectively represent the minimum, maximum, and average values. DES will produce valuable results for various subsequent analyses.

3.2.3. Submodel of Lean Analysis and Optimization. The submodel of lean analysis and optimization refers to the multidimensional analysis of the simulation results. The multidimensional analysis includes a production time analysis, a bottleneck workstation analysis, a resource utilization analysis, and a cost-benefit analysis. The production 


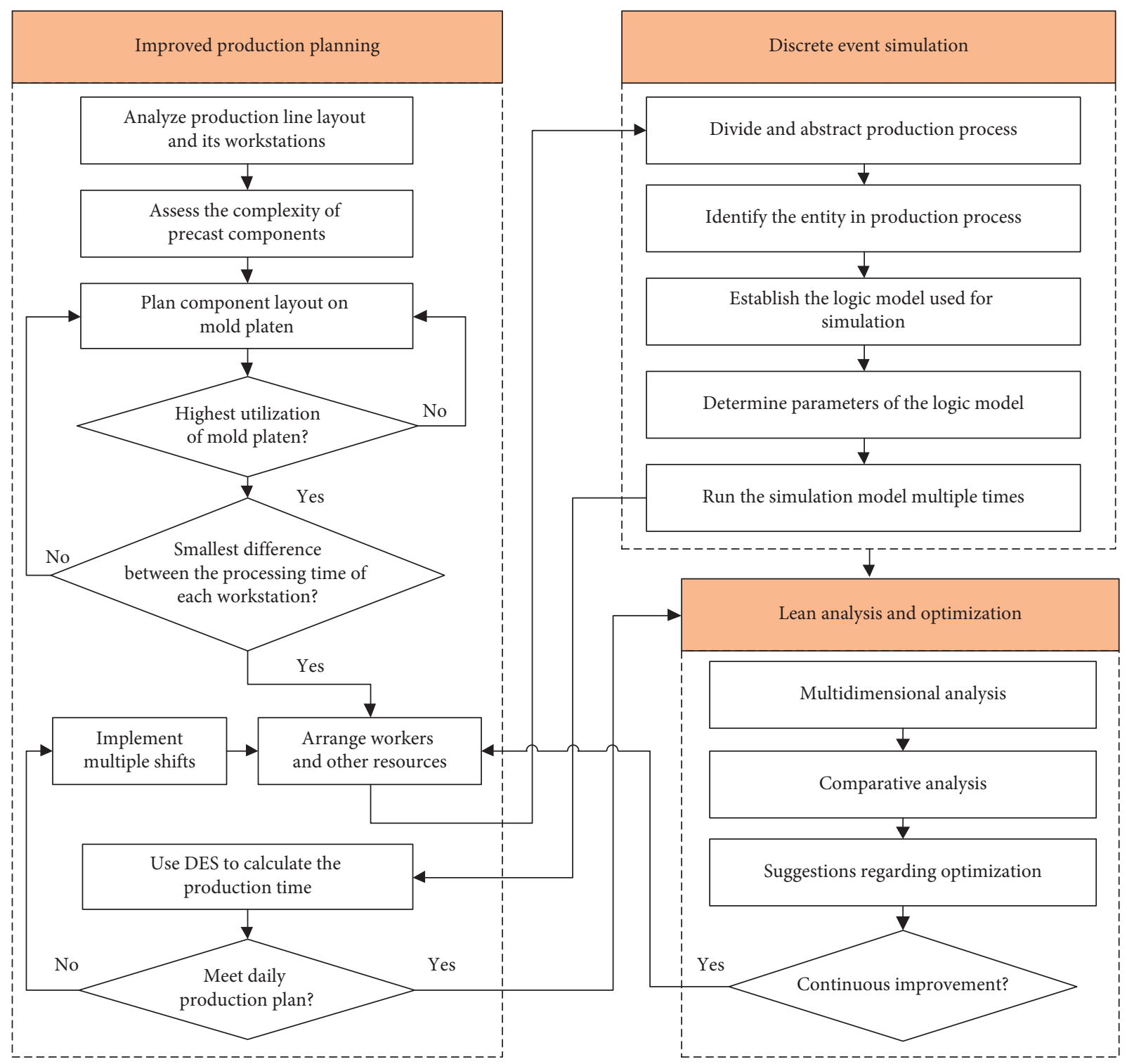

Figure 3: Framework for DES-based lean planning and optimization method.

TABLE 2: Complexity evaluation index system for precast components produced by assembly line.

\begin{tabular}{|c|c|c|c|}
\hline First-class index & Code & Second-class index & Weight \\
\hline \multirow{5}{*}{$\begin{array}{l}\text { Complexity of component } \\
\text { shape }\end{array}$} & 1 & Volume of component & $w_{1}$ \\
\hline & 2 & $\begin{array}{c}\text { Geometric shape of component (e.g., rectangle, triangle, circle, curved surface, "L" shape, } \\
\text { and "T" shape) }\end{array}$ & $w_{2}$ \\
\hline & 3 & Type and quantity of reserved holes for components & $w_{3}$ \\
\hline & 4 & Embedded window frame and window & $w_{4}$ \\
\hline & 5 & $\begin{array}{l}\text { Complexity of component surface and end surface (e.g., concrete washing surface, fair- } \\
\text { faced concrete, chiselling surface, and shear slot) }\end{array}$ & $w_{5}$ \\
\hline \multirow{4}{*}{$\begin{array}{l}\text { Complexity of component } \\
\text { composition }\end{array}$} & 6 & Complexity of component steel (e.g., steel content, steel location, and exposed steel) & $w_{6}$ \\
\hline & 7 & Type and quantity of embedded parts & $w_{7}$ \\
\hline & 8 & Type and quantity of grouting sleeve & $w_{8}$ \\
\hline & 9 & Setting of thermal insulation materials & $w_{9}$ \\
\hline \multirow{3}{*}{$\begin{array}{l}\text { Complexity of processing } \\
\text { technology }\end{array}$} & 10 & Cast times (e.g., one-time cast or multitimes cast) & \\
\hline & 11 & Processing technology of component in reverse position & $w_{11}$ \\
\hline & 12 & Prestressed processing technology & $w_{12}$ \\
\hline
\end{tabular}


time analysis takes the duration of each workstation as the basic element. The bottleneck workstation analysis aims to identify and analyse the workstation with the shortest duration. The resource utilization analysis is mainly used to identify idle resources. Resource utilization includes instantaneous utilization and scheduled utilization. Instantaneous utilization reflects how busy a resource is throughout the run. Instantaneous utilization is less than or equal to scheduled utilization. Formula (5) expresses the calculation mechanism of instantaneous utilization [62]. $f(t)$ is the number of resources that are busy at time $t . g(t)$ is the number of resources available at time $t$, including busy resources and idle resources.

$$
p(t)= \begin{cases}\frac{\int_{0}^{T} f(t) / g(t)}{T}, & g(t)>0, \\ 0, & g(t)=0 .\end{cases}
$$

The cost-benefit analysis is used to analyse the dynamic changes in performance, such as balance resources, save time, and reduce costs. Then, the comparative analysis between the simulation results and the original plan results is performed. The submodel of lean analysis and optimization not only includes a variety of lean analysis but also provides the detailed measures used to optimize the scheme. These detailed measures are to improve the production benefits continuously under the premise of meeting delivery time.

\section{A Case Study of Component Factory Production}

4.1. Basic Profile of the Case Study. Compared with other types of precast components, semiprecast slabs are produced on a production line called an assembly line. Mold platens corresponding to semiprecast slabs are mobile rather than fixed on this type of production line. Semiprecast slabs are processed step by step in sequence. Hence, semiprecast slabs are more representative in terms of industrialization. The data regarding a production line mainly used for semiprecast slab production is provided by a component factory, as shown in Figure 4. It only shows the part of the production line considering the confidential requirements from the component factory. The production line has a total of 33 workstations and a buffer, but a few workstations are not used for semiprecast slabs. In addition, some workstations have the same name and activity. Each flushed semiprecast slab will be temporarily stacked in a designated area within the workshop.

The production case of a project is further provided by the component factory. The project has a total of 17 buildings (1\# to $17 \#)$ with shear wall structures. The prefabrication rate of $1 \#$ building is $50.07 \%$. Semiprecast slabs are used for the 4 th 24 th floors of this building, and each floor owns 43 semiprecast slabs. The size of mold platen is $3.5 \mathrm{~m} \times 9 \mathrm{~m}$.

4.2. Complexity Evaluation of 43 Semiprecast Slabs. A technical engineer of this component factory is interviewed face-to-face once and consulted online three times. The complexity evaluation index system for precast components is sent to the technical engineer and her two colleagues. According to the characteristics of 43 semiprecast slabs, the three experts select and retain four complexity evaluation indices from the system and determine corresponding weights in the form of group discussion. The four indices and their corresponding weights are as follows: volume of component (weight $=0.05$ ), type and quantity of reserved holes for components (weight $=0.10$ ), complexity of component steel (weight $=0.60$ ), and type and quantity of embedded parts (weight $=0.25$ ). The following scoring rules are obtained from the original documents provided by the component factory: (1) the scoring of the reserved holes and embedded parts only needs to consider the quantity; (2) the scoring of the component steel only needs to consider the steel content. According to formula (1), the final complexity evaluation of 43 semiprecast slabs is shown in Figure 5. The $\mathrm{x} 1$ to $\mathrm{x} 43$ represent the code of each semiprecast slab, which is converted from the original code. The value range of the coordinate axis is 1 to 5 . The components $x 7$ and $x 17$ own the highest complexity 4.60 while the components $x 25$ and $x 35$ have the lowest complexity 1.00 .

\subsection{Processing Time for Each Workstation under Constraints.} The utilization of mold platens is regarded as a prior constraint for planning the component layout on mold platen. On this basis, the complexity of precast components is used to further optimize the layout. The principle of optimization is that the combination of complex components and simple components appears on a mold platen as much as possible. A total of 21 mold platens are used for the 43 semiprecast slabs through planning and optimization, which correspond to 43 molds. In view of the confidential requirements from the component factory, Figure 6 only shows eight component (or mold) layouts on four mold platens, which are from the 21 mold platens. These layouts take into account both the utilization of mold platens and the complexity of precast components. The $i$ takes an integer between 2 and 19 .

Some workstations (e.g., mold assembly workstations) in the production line are only used initially. Hence, it only considers a common production situation where the mold assembly workstations are no longer required. A production team of the production line has 40 workers. Considering the utilization of mold platens and the complexity of precast components, the name, number, activity, and time of each workstation used for semiprecast slabs are provided by the three experts, as shown in Table 3. Other workstations in the production line are regarded as transportation routes. Since the transport time of mold platen between workstations is very short, it is not considered. Resting workstation is a very special and flexible station. Multiple activities will be completed at this workstation, and preliminary solidified semiprecast slabs are allowed to stay here for a long time in special circumstances. The curing kiln owns 39 cells, which can store up to 39 mold platens. The triangular distribution is often used in the case of high data collection cost and low data accuracy [25], which is in line with this case. If the three 


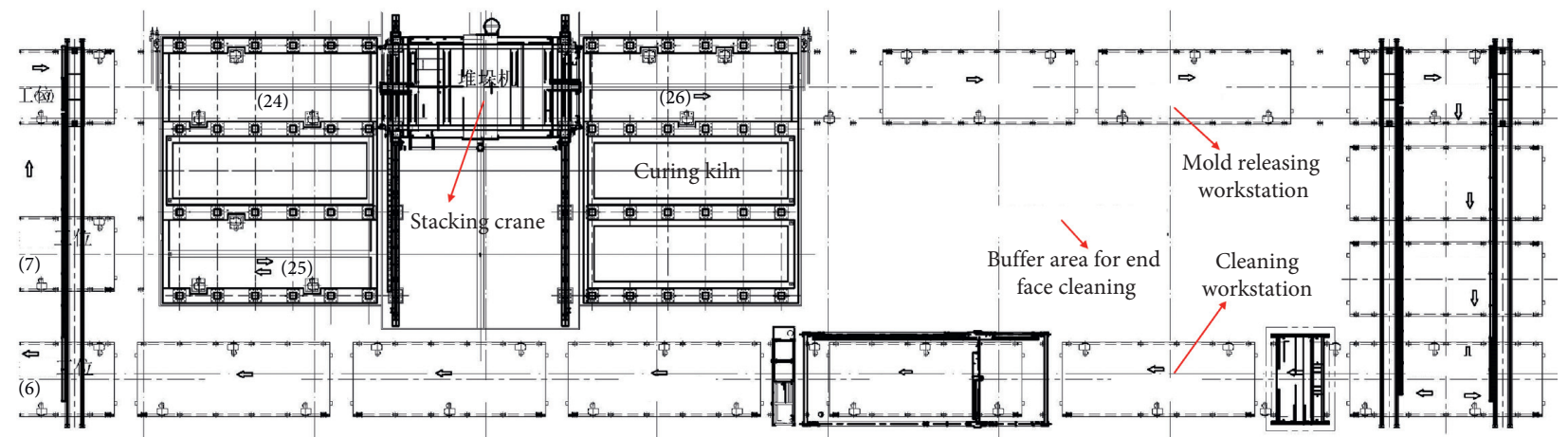

FIGURE 4: Production line diagram regarding semiprecast slabs.

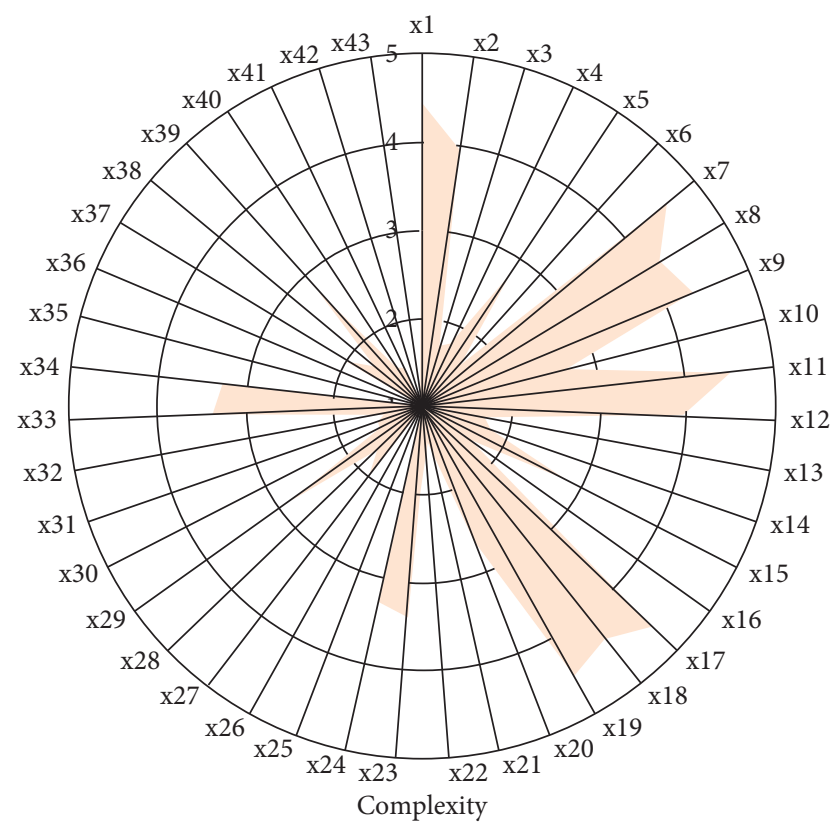

FIgURE 5: Complexity evaluation of 43 semiprecast slabs.

parameter values of triangular distribution are the same, triangular distribution is replaced by uniform distribution.

4.4. Logic Model and Simulation Results for Production Case. The production line of semiprecast slabs is abstracted into a discrete event simulation system. In the discrete event simulation system, a mold platen instead of a semiprecast slab is regarded as a virtual entity. Since the arrival time of the virtual entity is meaningless, it can be any minimal number. A mold platen arrives at a workstation and occupies it so that other mold platens cannot use the workstation. Hence, workstations are regarded as resources. Although workers, materials, and equipment are available as resources, only workstations are considered here. The location of mold platens moves with processing workstations. After the molds on mold platen are released, the mold platen and its corresponding molds will be returned to the cleaning station and reused again. The DES-based logic model regarding semiprecast slab production is established, as shown in Figure 7. The starting point of the model is the random arrival of mold platens. Some activities have been merged into the model. For example, mold preparing includes mod cleaning, mold platen cleaning, and antiadherent brushing.

In the Arena software, the terminating simulation mode is adopted instead of the steady-state simulation mode. The logical model is simulated 1500 times under the existing resource allocation, and the termination condition for each simulation is set to "Dispose 1.number out $<>21$ ". After the 1500 simulations, the total time of all entities is as follows: average total time (723.18 minutes), minimum average total time (712.90 minutes), maximum average total time (733.76 minutes), minimum total time (588.25 minutes), and maximum total time ( 866.35 minutes). This total time is also referred to as the production time for 43 semiprecast slabs, as shown in Figure 8.

The activities with waiting time include mold preparing (123.24 minutes), transport to curing kiln (0.44 minutes), and end face cleaning (0.01 minutes). Instantaneous utilization of each resource is shown in Table 4.

\subsection{Analysis and Discussion of Results}

4.5.1. Comparative Analysis between the Existing and Improved Methods. The existing production planning method for precast components fails to distinguish the difference between the processing time of each workstation and only selects a typical workstation processing time as takt time. The component factory previously adopted a typical workstation processing time (approximately 10 minutes) as takl time, and then the production time for the 21 mold platens was 11.50 hours $(21 \times 10 / 60+8=11.50 \mathrm{~h})$. If two shifts per day are implemented, two standard floors of semiprecast slabs will be produced per day, which meets the daily production plan. Compared with the existing production planning method, the DES-based lean planning and optimization method for precast components add the complexity assessment for precast components on the basis of the mold platen utilization. Besides, it can also capture the difference between the processing time of each workstation so as to provide more accurate results and richer information. After the layout of precast components on mold platen according to the utilization rate of mold platen, the combination results of precast components also need to be optimized according to the complexity of precast 


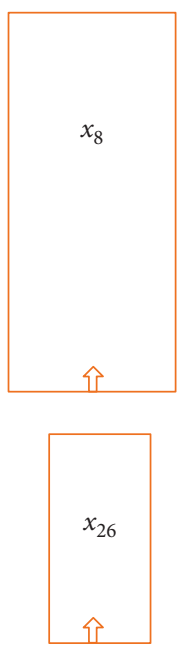

(a)

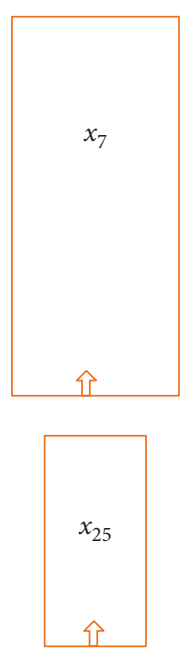

(b)
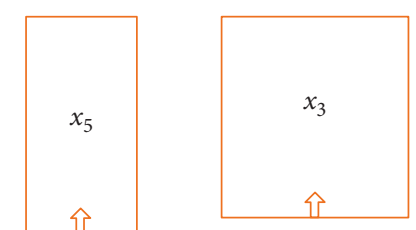

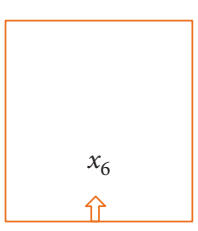

(c)

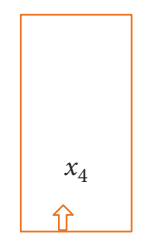

(d)

Figure 6: Eight component layouts on four mold platens. (a) Mold platen $i-1$. (b) Mold platen $i$. (c) Mold platen $i+1$. (d) Mold platen $i+2$.

TABLe 3: Name, activity, number, and time of each workstation used for semiprecast slabs.

\begin{tabular}{|c|c|c|c|c|c|c|}
\hline \multirow[b]{2}{*}{ Code } & \multirow[b]{2}{*}{ Name } & \multirow[b]{2}{*}{ Activities } & \multirow[b]{2}{*}{ Number } & \multicolumn{3}{|c|}{ Time (minute) } \\
\hline & & & & Min & $\begin{array}{l}\text { Most } \\
\text { likely }\end{array}$ & Max \\
\hline 1 & Cleaning workstation & $\begin{array}{c}\text { Mold preparing, including mod cleaning, mold platen cleaning, } \\
\text { and antiadherent brushing }\end{array}$ & 1 & 10 & 12 & 15 \\
\hline 2 & Steel installation workstation & $\begin{array}{l}\text { Steel installing, including steel into mold and binding, as well as } \\
\text { embedded part laying }\end{array}$ & 6 & 20 & 25 & 30 \\
\hline 3 & $\begin{array}{l}\text { Checking workstation before } \\
\text { concrete pouring }\end{array}$ & $\begin{array}{c}\text { Checking work, namely, whether steel and embedded part and } \\
\text { others meet the design requirements }\end{array}$ & 2 & 10 & 12 & 15 \\
\hline 4 & $\begin{array}{l}\text { Concrete pouring and vibrating } \\
\text { workstation }\end{array}$ & Concrete pouring and vibrating & 2 & 10 & 12 & 15 \\
\hline 5 & Resting workstation & $\begin{array}{l}\text { Initial setting and scratching } \\
\text { Resting }\end{array}$ & 4 & $\begin{array}{c}5 \\
10\end{array}$ & $\begin{array}{c}7.5 \\
15\end{array}$ & $\begin{array}{l}10 \\
20\end{array}$ \\
\hline 6 & Stacking crane & Transport to curing kiln & 1 & 5 & 7.5 & 10 \\
\hline 7 & Curing kiln & Steam curing & 1 & 480 & 480 & 480 \\
\hline 8 & Mold releasing workstation & Mold releasing & 6 & 15 & 17.5 & 20 \\
\hline 9 & Buffer area for end face cleaning & End face cleaning & 1 & 5 & 5 & 5 \\
\hline 10 & Temporary stacking area & Temporary stacking & 1 & 5 & 5 & 5 \\
\hline
\end{tabular}

components. According to Figure 8, the average production time calculated by this method is 12.05 hours (723.18/ $60=12.05 \mathrm{~h}$ ). According to this calculation result, it seems to be difficult to realize two shifts per day, which means that the daily production plan regarding two standard floors cannot be achieved in one day. Besides, the information captured by the method also includes other types of production time, the activities with waiting time, and the instantaneous utilization of each resource. This information or data will provide decision-makers with a deeper analysis and reference.

4.5.2. Workstation Utilization Analysis under Existing Resource Allocation. Activities within 1 minute are more flexible and easily overlooked in the production process of semiprecast slabs. Although the waiting time of mold preparing is much larger than 1 minute, it does not affect the total time. Therefore, there is no bottleneck workstation under the existing resource allocation. However, some workstations (or resources) are idle. This goes against the lean principle and is not conducive to the factory's sustainable development. The average instantaneous utilization of each workstation is shown in Figure 9. The cleaning workstation owns the highest instantaneous utilization of 0.3057 . Hence, the instantaneous utilization of all workstations does not exceed $50 \%$. This means that some same workstations will be idle. The maximum number of steel installation stations in a busy state is 3 , which is consistent with the information provided by the factory staff interviewed. From the perspective of lean management, the component factory is suggested to make full use of the idle workstations to produce those precast components suitable for fixed mold platens.

4.5.3. Decision Analysis of Future Production Planning. The component factory expects that the semiprecast slabs of two standard floors are produced per day. The expected 


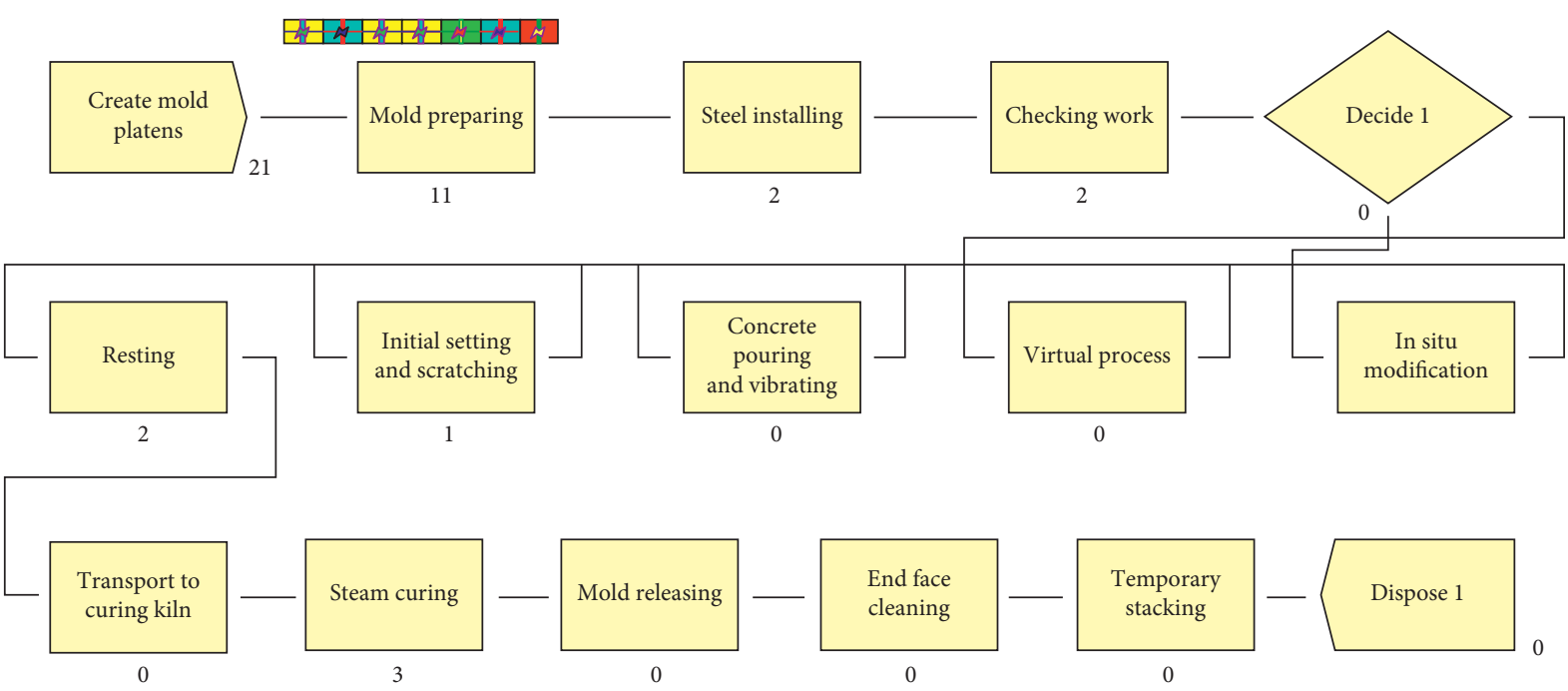

FiguRE 7: Logic model regarding precast component production.

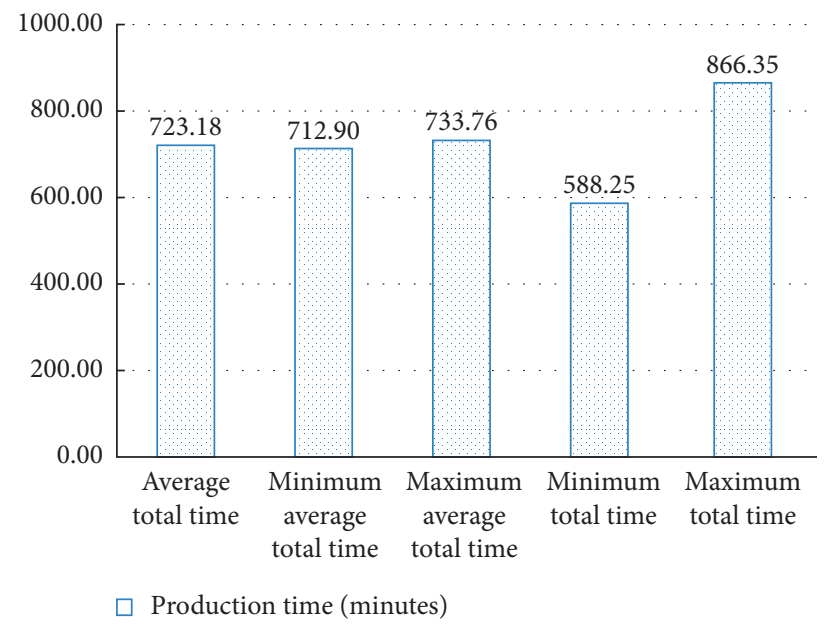

FIgURE 8: Production time for 43 semiprecast slabs.

TABLE 4: Instantaneous utilization of each resource after 1500 simulations.

\begin{tabular}{lcccc}
\hline Code & Name & \multicolumn{3}{c}{ Instantaneous utilization of resource } \\
Minimum average & Maximum average \\
\hline 1 & Cleaning workstation & 0.3057 & 0.2926 & 0.3186 \\
2 & Steel installation workstation & 0.1034 & 0.0969 & 0.1092 \\
3 & Checking workstation before concrete pouring & 0.1533 & 0.1440 & 0.1634 \\
4 & Concrete pouring and vibrating workstation & 0.1529 & 0.1444 & 0.1621 \\
5 & Resting workstation & 0.1394 & 0.1292 & 0.1503 \\
6 & Stacking crane & 0.1861 & 0.1695 & 0.2051 \\
7 & Curing kiln & 0.3053 & 0.2983 & 0.3120 \\
8 & Mold releasing workstation & 0.0723 & 0.0686 & 0.0755 \\
9 & Buffer area for end face cleaning & 0.1240 & 0.1212 & 0.1267 \\
10 & Temporary stacking area & 0.1240 & 0.1212 & 0.1267 \\
\hline
\end{tabular}

production time of one standard floor should be controlled within 11.5 hours considering some necessary reservation time. However, the 1500 simulation results under existing production capability show that this expected production time is difficult to achieve although it is feasible to a certain extent. The comparison of 1500 simulation results with the expected production time is shown in Figure 10. The expected production time (690 minutes) is located between minimum total time (588.25 minutes) and minimum average total time (712.90 minutes). A learning curve exists in 


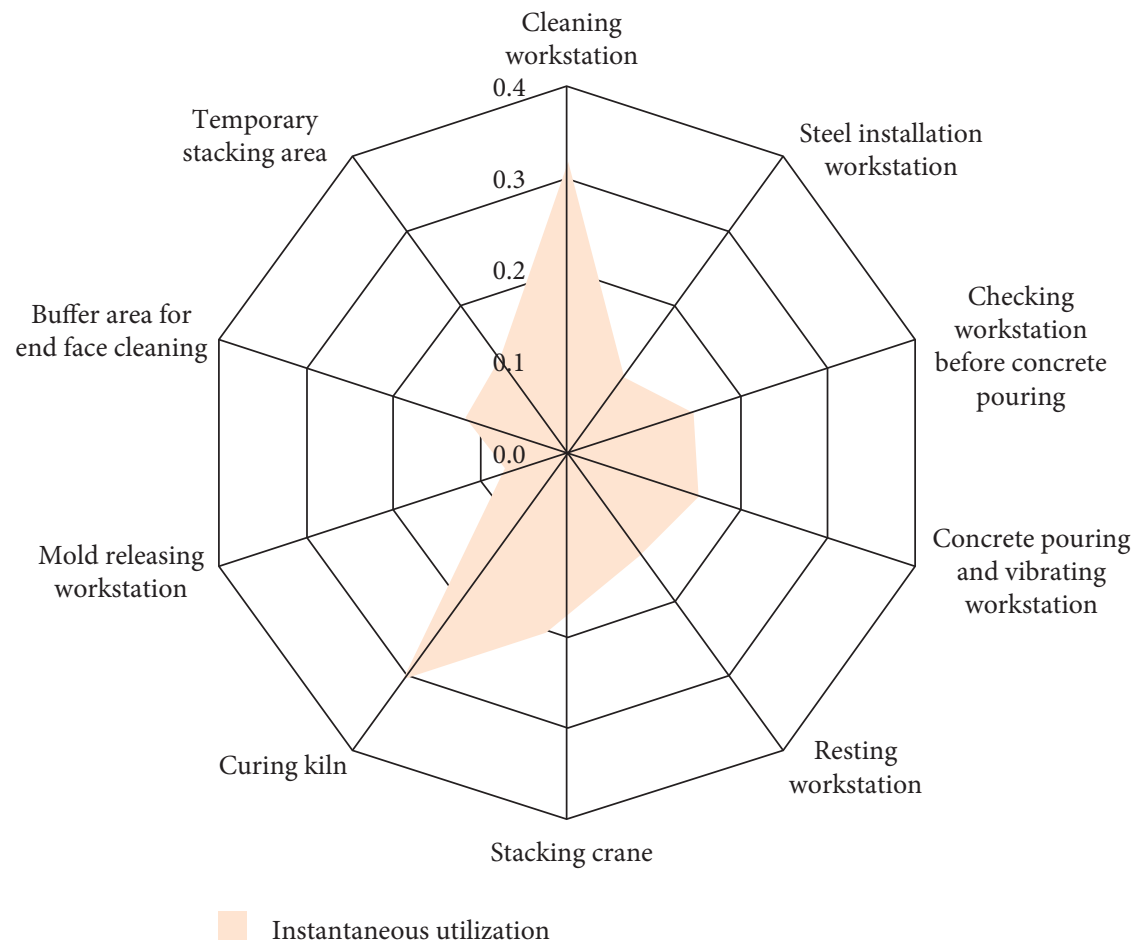

Figure 9: Average instantaneous utilization of each workstation.

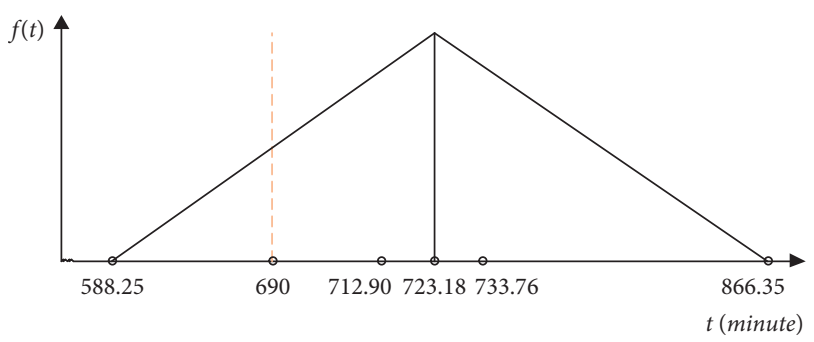

FIGURE 10: Comparison of simulation results with expected production schedule.

the production process of precast components [63]. After the workers in the component factory are skilled in their own work, the time spent on each workstation will be reduced so as to achieve the expected production time and two shifts per day. Hence, the key is how to shorten the time from unskilled to skilled in work. The component factory is suggested to pay more attention to the learning abilities and incentives of workers for improving work efficiency.

A semistructured interview is conducted with a technical engineer in the component factory. It is learned from the interview that the component factory intends to purchase a set of automatic equipment for steel processing. According to the 1500 simulation results, this will bring some advantages and disadvantages to the component factory. The advantages are as follows: (1) enhancing the automation level of semiprecast slab production; (2) reducing labor costs; (3) improving the accuracy of steel processing. In contrast, the disadvantages are as follows: (1) further increasing the idle rate of steel installation workstation; (2) not shortening the total production time; (3) adding additional equipment costs. Hence, we recommend that the component factory consider whether to purchase the automatic equipment again on the basis of cost-benefit analysis. Benefits in costbenefit analysis should be as comprehensive as possible, including profit, time, quality, and automation.

\section{Conclusions and Future Work}

In order to improve the accuracy of production time prediction and eliminate unnecessary waste in terms of time and resource utilization, this study develops a DES-based lean planning and optimization method for precast component production. Besides, a complexity evaluation index system for precast components produced is established through the investigation, consultation, and practice. Compared with the existing production planning method, the DES-based lean planning and optimization method has the following advantages: (1) the submodel of improved production planning considers not only the utilization of mold platen but also the complexity evaluation of precast components to minimize the difference between the processing time of each workstation; (2) the submodel of discrete event simulation can capture the uncertainty during precast component production to improve the accuracy of production time prediction; (3) the submodel of lean analysis and optimization can eliminate unnecessary waste in terms of time and resource utilization through the multidimensional analysis and comparative analysis.

Subsequently, one of the several project production cases is used to simulate and test the proposed method. Four complexity evaluation indices and their corresponding weights are respectively retained and determined by the 
three experts of the component factory. According to the layout of precast components on mold platen and the layout of production line, the DES-based logic model regarding semiprecast slab production is established. After the 1500 simulations, the expected production time (690 minutes) is located between minimum total time (588.25 minutes) and minimum average total time (712.90 minutes). The instantaneous utilization of all workstations does not exceed $50 \%$. For the specific case, the analysis results are as follows: (1) there is no bottleneck workstations under the existing resource allocation, but the utilization of each workstation is not high; (2) it is difficult to achieve the two shifts per day although it is feasible to a certain extent; (3) the option to purchase the automatic equipment used for steel processing does not shorten the total production time of semiprecast slabs. The suggestions regarding optimization are as follows:

(1) The new method developed by this study is recommended for component factories to improve the accuracy of production time prediction (concluded from Section 4.5.1). This method takes into account the complexity of precast components based on the utilization rate of mold platens to minimize the difference in the processing time of each workstation. In the calculation of the production time, it takes into account the uncertainty of the processing time of each workstation rather than taking a rough estimate.

(2) Component factories are suggested to pay more attention to the learning abilities and incentives of workers for improving work efficiency (concluded from Section 4.5.2). According to the consultation, the performance from the learning abilities and incentives can shorten the production time by one hour or more.

(3) Component factories are suggested to make full use of the idle workstations to produce those precast components suitable for fixed mold platens (concluded from Section 4.5.3). Lean management aims to eliminate all waste, especially unnecessary waste. The idleness of the workstation is obviously a waste that needs to be used.

The established method proposes a new idea for improving the accuracy of production time prediction and eliminating unnecessary waste. It further expands the boundary of lean production methodology from the perspective of the construction industry rather than the manufacturing industry. The findings and suggestions will provide a valuable reference and guidance for component factories to make detailed and optimal daily production plans. However, the complexity evaluation index system established in this study only considers some common precast components produced on assembly lines, such as precast wallboards and semiprecast slabs. Some special and uncommon precast components may be produced on assembly lines. Hence, they may be future research directions to continuously improve the complexity evaluation index system and thoroughly analyse the impact of the complexity for precast components on production.

\section{Data Availability}

All data used to support the findings of this study are included within the article.

\section{Conflicts of Interest}

The authors declare that there are no conflicts of interest regarding the publication of this paper.

\section{Acknowledgments}

The authors are grateful to all the experts, companies, and institutions that provided assistance for this research. This research was funded by the Fundamental Research Funds for the Central Universities (Project no. 2020QN73) and the National Natural Science Foundation of China (Project no. 51878026).

\section{References}

[1] Y. Chang, X. Li, E. Masanet, L. Zhang, Z. Huang, and R. Ries, "Unlocking the green opportunity for prefabricated buildings and construction in China," Resources Conservation and Recycling, vol. 139, pp. 259-261, 2018.

[2] Y. H. Chian, V. J. Li, L. Zhou, and F. Wong, "Evaluating sustainable building-maintenance projects: balancing economic, social, and environmental impacts in the case of Hong Kong," Journal of Construction Engineering and Management, vol. 142, no. 2, https://www.researchgate.net/deref/http\%3A\% 2F\%2Fdx.doi.org\%2F10.1061\%2F(ASCE)CO.1943-7862. 0001065, Article ID 06015003, 2016.

[3] R. Jin, J. Hong, and J. Zuo, "Environmental performance of off-site constructed facilities: a critical review," Energy and Buildings, vol. 207, Article ID 109567, 2020.

[4] H. X. Li, L. Zhang, D. Mah, and H. Yu, "An integrated simulation and optimization approach for reducing $\mathrm{CO} 2$ emissions from on-site construction process in cold regions," Energy and Buildings, vol. 138, pp. 666-675, 2017.

[5] H. X. Li, M. Al-Hussein, Z. Lei, and Z. Ajweh, "Risk identification and assessment of modular construction utilizing fuzzy analytic hierarchy process (AHP) and simulation," Canadian Journal of Civil Engineering, vol. 40, no. 12, pp. 1184-1195, 2013.

[6] C. Z. Li, J. Hong, C. Fan, X. Xu, and G. Q. Shen, "Schedule delay analysis of prefabricated housing production: a hybrid dynamic approach," Journal of Cleaner Production, vol. 195, pp. 1533-1545, 2018.

[7] T. Yu, Q. Man, Y. Wang et al., "Evaluating different stakeholder impacts on the occurrence of quality defects in offsite construction projects: a Bayesian-network-based model," Journal of Cleaner Production, vol. 241, Article ID 118390, 2019.

[8] C. Z. Li, J. Hong, F. Xue, G. Q. Shen, X. Xu, and L. Luo, "SWOT analysis and Internet of Things-enabled platform for prefabrication housing production in Hong Kong," Habitat International, vol. 57, pp. 74-87, 2016. 
[9] C. Z. Li, F. Xue, X. Li, J. Hong, and G. Q. Shen, “An Internet of Things-enabled BIM platform for on-site assembly services in prefabricated construction," Automation in Construction, vol. 89, pp. 146-161, 2018.

[10] J. Hong, G. Q. Shen, Z. Li, B. Zhang, and W. Zhang, "Barriers to promoting prefabricated construction in China: a costbenefit analysis," Journal of Cleaner Production, vol. 172, pp. 649-660, 2018.

[11] X. Chen, Z. Wang, and Y. Liang, "Research on optimization of production workshop layout of concrete precast components based on genetic algorithm," Journal of Engineering Management, vol. 33, no. 3, pp. 36-41, 2019, (in Chinese).

[12] X. Li, Z. Li, and G. Wu, "Lean precast production system based on the CONWIP method," KSCE Journal of Civil Engineering, vol. 22, no. 7, pp. 2167-2177, 2018.

[13] Z. Wang and H. Hu, "Improved precast production-scheduling model considering the whole supply chain," Journal of Computing in Civil Engineering, vol. 31, no. 4, Article ID 04017013, 2017.

[14] A. Khalili and D. K. Chua, "Integrated prefabrication configuration and component grouping for resource optimization of precast production," Journal of Construction Engineering and Management, vol. 140, no. 2, Article ID 04013052, 2014.

[15] D. Wang, G. Liu, K. Li et al., "Layout optimization model for the production planning of precast concrete building components," Sustainability, vol. 10, no. 6, p. 1807, 2018.

[16] A. Al-Bazi and N. Dawood, "Developing crew allocation system for the precast industry using genetic algorithms," Computer-Aided Civil and Infrastructure Engineering, vol. 25, no. 8, pp. 581-595, 2010.

[17] V. Benjaoran and N. Dawood, "Intelligence approach to production planning system for bespoke precast concrete products," Automation in Construction, vol. 15, no. 6, pp. 737-745, 2006

[18] J.-H. Chen, S. Yan, H.-W. Tai, and C. Chang, "Optimizing profit and logistics for precast concrete production," Canadian Journal of Civil Engineering, vol. 44, no. 6, pp. 393-406, 2017.

[19] G. Liu, T. Gu, P. Xu, J. Hong, A. Shrestha, and I. Martek, “A production line-based carbon emission assessment model for prefabricated components in China," Journal of Cleaner Production, vol. 209, pp. 30-39, 2019.

[20] C. Chang and Y. Zhang, "Research on the problems and measures of production cost control in prefabricated building component," Journal of Shenyang Jianzhu University (Social Science), vol. 18, no. 5, pp. 470-475, 2016, (in Chinese).

[21] J.-H. Chen, L.-R. Yang, and H.-W. Tai, "Process reengineering and improvement for building precast production," Automation in Construction, vol. 68, pp. 249-258, 2016.

[22] J. J. Ochoa, "Reducing plan variations in delivering sustainable building projects," Journal of Cleaner Production, vol. 85, pp. 276-288, 2014.

[23] S. H. Han, M. Al-Hussein, S. Al-Jibouri, and H. Yu, "Automated post-simulation visualization of modular building production assembly line," Automation in Construction, vol. 21, pp. 229-236, 2012.

[24] M. Arashpour, R. Wakefield, N. Blismas, and J. Minas, "Optimization of process integration and multi-skilled resource utilization in off-site construction," Automation in Construction, vol. 50, pp. 72-80, 2015.

[25] M. Arashpour, V. Kamat, Y. Bai, R. Wakefield, and B. Abbasi, "Optimization modeling of multi-skilled resources in prefabrication: theorizing cost analysis of process integration in off-site construction," Automation in Construction, vol. 95, pp. 1-9, 2018.

[26] C. Z. Li, G. Q. Shen, X. Xu, F. Xue, L. Sommer, and L. Luo, "Schedule risk modeling in prefabrication housing production," Journal of Cleaner Production, vol. 153, no. 1, pp. 692-706, 2017.

[27] J. Jo, J. Huh, J. Park, B. Kim, and J. Seo, "Live Gantt: interactively visualizing a large manufacturing schedule," IEEE Transactions on Visualization and Computer Graphics, vol. 20, no. 12, pp. 2329-2338, 2014.

[28] T. Hegazy, E. Elbeltagi, and K. Zhang, "Keeping better site records using intelligent bar charts," Journal of Construction Engineering and Management, vol. 131, no. 5, pp. 513-521, 2005.

[29] S. AbouRizk, "Role of simulation in construction engineering and management," Journal of Construction Engineering and Management, vol. 136, no. 10, pp. 1140-1153, 2010.

[30] N. Sadeghi, A. Robinson Fayek, and N. Gerami Seresht, "Queue performance measures in construction simulation models containing subjective uncertainty," Automation in Construction, vol. 60, pp. 1-11, 2015.

[31] G. Demiralp, G. Guven, and E. Ergen, "Analyzing the benefits of RFID technology for cost sharing in construction supply chains: a case study on prefabricated precast components," Automation in Construction, vol. 24, pp. 120-129, 2012.

[32] I. D. Tommelein, "Pull-driven scheduling for pipe-spool installation: simulation of lean construction technique," Journal of Construction Engineering and Management, vol. 124, no. 4, pp. 279-288, 1998.

[33] Z. Wang and H. Hu, "Dynamic response to demand variability for precast production rescheduling with multiple lines," International Journal of Production Research, vol. 56, no. 16, pp. 5386-5401, 2018.

[34] C.-H. Ko, "An integrated framework for reducing precast fabrication inventory," Journal of Civil Engineering and Management, vol. 16, no. 3, pp. 418-427, 2010.

[35] Z. Ma, Z. Yang, S. Liu, and S. Wu, "Optimized rescheduling of multiple production lines for flowshop production of reinforced precast concrete components," Automation in Construction, vol. 95, pp. 86-97, 2018.

[36] Z. Wang, H. Hu, and J. Gong, "Framework for modeling operational uncertainty to optimize offsite production scheduling of precast components," Automation in Construction, vol. 86, pp. 69-80, 2018.

[37] Z. Wang, H. Hu, J. Gong, and X. Ma, "Synchronizing production scheduling with resources allocation for precast components in a multi-agent system environment," Journal of Manufacturing Systems, vol. 49, pp. 131-142, 2018.

[38] Z. Yang, Z. Ma, and S. Wu, "Optimized flowshop scheduling of multiple production lines for precast production," Automation in Construction, vol. 72, pp. 321-329, 2016.

[39] M. Podolski and M. Rejment, "Scheduling the production of precast concrete elements using the simulated annealing metaheuristic algorithm," IOP Conference Series-Materials Science and Engineering, vol. 471, Article ID 112083, 2019.

[40] M. S. Altaf, A. Bouferguene, H. Liu, M. Al-Hussein, and $\mathrm{H}$. $\mathrm{Yu}$, "Integrated production planning and control system for a panelized home prefabrication facility using simulation and RFID," Automation in Construction, vol. 85, pp. 369-383, 2018.

[41] R. Sundar, A. N. Balaji, and R. M. S. Kumar, "A review on lean manufacturing implementation techniques," Procedia Engineering, vol. 97, pp. 1875-1885, 2014. 
[42] P. Ranky, "Eighteen "monozukuri-focused" assembly line design and visual factory management principles with DENSO industrial examples," Assembly Automation, vol. 27, no. 1, pp. 12-16, 2007.

[43] L. Koskela, Application of the New Production Philosophy to Construction, CIFE (Center for Integrated Facility Engineering, Finland, 1992.

[44] O. Koseoglu, M. Sakin, and Y. Arayici, "Exploring the BIM and lean synergies in the Istanbul Grand Airport construction project," Engineering Construction and Architectural Management, vol. 25, no. 10, pp. 1339-1354, 2018.

[45] P. Uusitalo, O. Seppanen, A. Peltokorpi, and H. Olivieri, "Solving design management problems using lean design management: the role of trust," Engineering Construction and Architectural Management, vol. 26, no. 7, pp. 1322-1338, 2019.

[46] A. A. E. Othman and M. H. M. Khalil, "Lean talent management: a novel approach for increasing creativity in architectural design firms," Engineering Construction and Architectural Management, vol. 25, no. 10, pp. 1355-1375, 2018.

[47] L. E. Bygballe, M. Endresen, and S. Fålun, "The role of formal and informal mechanisms in implementing lean principles in construction projects," Engineering Construction and Architectural Management, vol. 25, no. 10, pp. 1322-1338, 2018.

[48] H. Yu, M. Al-Hussein, S. Al-Jibouri, and A. Telyas, "Lean transformation in a modular building company: a case for implementation," Journal of Management in Engineering, vol. 29, no. 1, pp. 103-111, 2013.

[49] G. Heravi and M. Firoozi, "Production process improvement of buildings' prefabricated steel frames using value stream mapping," International Journal of Advanced Manufacturing Technology, vol. 89, no. 9-12, pp. 3307-3321, 2017.

[50] F. Innella, M. Arashpour, and Y. Bai, "Lean methodologies and techniques for modular construction: chronological and critical review," Journal of Construction Engineering and Management, vol. 45, no. 12, Article ID 04019076, 2019.

[51] X. Li, G. Q. Shen, P. Wu, H. Fan, H. Wu, and Y. Teng, "RBLPHP: simulation of lean construction and information technologies for prefabrication housing production," Journal of Management in Engineering, vol. 34, no. 2, Article ID 04017053, 2018.

[52] K. Feng, W. Lu, T. Olofsson, S. Chen, and Y. Wang, “An integrated environment-cost-time optimisation method for construction contractors considering global warming," Sustainability, vol. 10, no. 11, Article ID 4207, 2018.

[53] K. Feng, W. Lu, T. Olofsson, S. Chen, H. Yan, and Y. Wang, "A predictive environmental assessment method for construction operations: application to a northeast China case study," Sustainability, vol. 10, no. 11, Article ID 3868, 2018.

[54] J. Slomp, J. A. C. Bokhorst, and R. Germs, "A lean production control system for high-variety/low-volume environments: a case study implementation," Production Planning \& Control, vol. 20, no. 7, pp. 586-595, 2009.

[55] J.-C. Lu and T. Yang, "Implementing lean standard work to solve a low work-in-process buffer problem in a highly automated manufacturing environment," International Journal of Production Research, vol. 53, no. 8, pp. 2285-2305, 2015.

[56] H. R. Thomas, M. Horman, R. Minchin, and D. Chen, "Improving labor flow reliability for better productivity as lean construction principle," Journal of Construction Engineering and Management-ASCE, vol. 129, no. 3, pp. 251-261, 2003.

[57] H. Said, "Prefabrication best practices and improvement opportunities for electrical construction," Journal of
Construction Engineering and Management, vol. 141, no. 12, Article ID 04015045, 2015.

[58] W. Y. Ji, S. M. AbouRizk, O. R. Zaiane, and Y. T. Li, "Complexity analysis approach for prefabricated construction products using uncertain data clustering," Journal of Construction Engineering and Management, vol. 144, no. 8, Article ID 04018063, 2018.

[59] K. R. Antani, "A study of the effects of manufacturing complexity on product quality in mixed-model automotive assembly," All Dissertations, vol. 14, Article ID 1540, 2014.

[60] K. Park and G. E. Okudan Kremer, "Assessment of static complexity in design and manufacturing of a product family and its impact on manufacturing performance,", International Journal of Production Economics, vol. 169, pp. 215-232, 2015.

[61] M. Fera, R. Macchiaroli, F. Fruggiero, and A. Lambiase, "A new perspective for production process analysis using additive manufacturing-complexity vs production volume," International Journal of Advanced Manufacturing Technology, vol. 95, no. 2, pp. 673-685, 2018.

[62] D. Chang, D. Li, and W. Liao, "The construction and simulation of mobile commerce process based on grid management," Business, vol. 14, pp. 859-864, 2013.

[63] S. Xie and X. Chen, "Two phase job-shop scheduling optimization for prefabricated construction projects based on multilayer coding genetic algorithm," Journal of Engineering Management, vol. 32, no. 1, pp. 18-22, 2018, in Chinese. 